Original Article

\title{
Knowledge and Acceptance of HPV Vaccination among Women Attending at Out Patient Department of Dhaka Medical College Hospital
}

\author{
${ }^{*}$ Lipi $L B^{1}$, Rahman $M M^{2}$, Shaha $N^{3}$, Sultana $M^{4}$, Ara $P^{5}$
}

\begin{abstract}
Vaccination is a part of primary prevention to prevent cervical cancer. The causative agent of cervical cancer is Human Papilloma Virus (HPV). The purpose of this study was to assess the knowledge and awareness regarding cervical cancer prevention by $H P V$ vaccination and acceptance of vaccination among women attending at outpatient department of Dhaka Medical College Hospital. A qualitative study was undertaken using face to face in depth interviews from July 2015 to December 2015. A total of 229 women were included and their

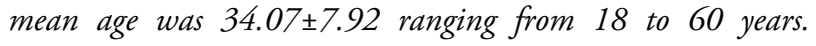
Awareness and knowledge about cervical cancer was very poor. Only 22.7\% participants were aware of HPV vaccination. Knowledge was high among women coming from high socioeconomic condition which was $31.5 \% \quad(p=0.03)$. Participants who were highly educated had more knowledge on vaccination about $66.7 \%(p=0.001)$. There was a high acceptance (83.8\%) of HPV vaccination among participants. The findings focus on the importance of awareness development on cervical cancer and its risk factors. Continuous screening of cervical cancer for early diagnosis and prompt treatment and
\end{abstract}

1. *Dr. Lutfa Begum Lipi, junior Consultant, Department of obstretics and gynaecology, Dhaka Medical College Hospital, Dhaka. Email:lutfa.ssmc@gmail.com

2. Dr. Mohammed Mizanur Rahman,associate prof, department of Urology, National Institute Of Kidney Diseases And Urology,Dhaka

3. Dr. Nibedita Shaha, Assistant Registrar, Department of obstretics and gynaecology, Dhaka Medical College Hospital, Dhaka.

4. Dr.Meher Sultana, Assistant registrar, Department of obstretics and gynaecology, Dhaka Medical College Hospital, Dhaka.

5. Prof. Iffat Ara, Proffesor, Department of obstretics and gynaecology, Popular Medical College,Dhaka.

${ }^{*}$ Corresponding Author publicity of awareness development program by mass-media (television, cable line add etc.), poster, billboard and most importantly through health education could play an important role in cervical cancer prevention.

Key Words: Human Papilloma Virus,vaccination, primary prevention, cervical cancer

\section{INTRODUCTION:}

Among the total global cervical cancer $80 \%$ occur in developing country.1 Globally- 527624 new cases - half the global burden is in Asia ,one quarter in Southern Asia.2 In Bangladesh yearly burden of cervical cancer is about 17686 and around 10364 women die from cervical cancer each year. 3 Hospital based data revealed that cervical cancer constitutes $22-29 \%$ of female cancer in Bangladesh.4 Interestingly, the disease is excellently preventable. Cancer prevention is action taken to lower the chance of getting cancer. By preventing cancer, the number of new cases of cancer in a group or population is lowered. Hopefully, this will lower the number of deaths caused by cancer. To prevent new cancers from starting, scientists look at risk factors and protective factors. Anything that increases the chance of developing cancer is called a cancer risk factor; anything that decreases the chance of developing cancer is called a cancer protective factor.

Avoiding risk factors and increasing protective factors may help prevent cancer . Risk factors for cervical cancer are the human papilloma virus infection(HPV) (a common sexually transmitted virus), having sex at an early age, multiple sexual partners, Smoking or using tobacco, using birth control pills for a long time, weakened immune system- such as those who have human immunodeficiency virus (HIV) infection, been exposed to diethylstilbestrol (DES) before birth. The protective factors that decrease the risk of cervical cancer is HPV vaccination. So vaccination is a part of primary prevention to prevent cervical cancer.

Cervical cancer is almost always caused by human papilloma virus (HPV) infection that spreads through sexual contact.5 There are more than 150 types of human papilloma virus that infect cervix, vagina, vulva, anus and about 30 of these can infect the cervix. Human Papilloma Virus (HPV) type 16 and 18 contributes to over $70 \%$ of all cervical cancer cases.6-8 
Bangladesh is a developing country with limited resources. The Government of Bangladesh (GOB) has developed wide cervical cancer screening program through Visual Inspection of Cervix with Acetic Acid (VIA).9

The services for cervical and breast cancer screening are currently available as opportunistic screening at 252 facilities including Bangabandhu Sheikh Mujib Medical University (BSMMU), Medical College Hospitals, District Hospitals, Maternal and Child Welfare Centers, Upozilla Health Complexes (UHC), Union Health \& Family Welfare Centers (UH\&FWC), Urban Primary Health Care centers and Non-Government Organizations (NGO). The trained Family Welfare Visitors (FWVs), Senior Staff Nurses (SSNs) and Doctors offer VIA to detect the pre-cancer or early stages of cervical cancer among women 30 years and above visiting the mentioned centers.10 VIA positive women are referred to BSMMU and various government $\mathrm{MCH}$ s for colposcopic evaluation and necessary management. This service is technically and financially supported by GOB, BSMMU and UNFPA.10,11

However, only three lac women have received screening services during the last five years. 12 During evaluation of the 'Cervical Cancer Screening Program of Bangladesh' low coverage of the target population was observed. Lack of awareness about cervical cancer and its prevention, low availability of services may be underlying factors for this low intake of services. In fact, several studies have mentioned that the uptake of screening in developing countries is poor .13 Lack of awareness of cervical cancer has been identified as one of the factors contributing to the high prevalence of this condition in the developing world compared to the developed one.14 Unlike developed countries, cervical cancer prevention program have failed to meet their objectives in developing countries due to financial, social and logistical problems. 15

Vaccination against the human papilloma virus in women before sexual activity also prevents cervical cancer.16-19 Vaccines are available that can protect against certain HPV infections. HPV vaccines that have been developed are based on recombinant expression and self assembly of the major capsid protein-1 into virus like practical (VPLs) that resemble the outer capsid of whole virus. The HPV VPLs contain no DNA and are not live attenuated virus. Three vaccines are approved by the FDA to prevent HPV infection: Gardasil, Gardasil 9, and Cervarix. All three vaccines prevent infections with HPV types 16 and 18, two high risk HPV typethat cause about $70 \%$ of cervical cancers and an even higher percentage of some of the other HPV-associated cancers. Gardasil also prevents infection with HPV types 6 and 11 , which cause $90 \%$ of genital warts . Gardasil 9 prevents infection with the same four HPV types plus five additional high-risk HPV types $(31,33,45,52$, and 58).20,21

To decrease the country wise and global burden of the disease, the community perception regarding disease process, progression, screening and prevention by vaccination have to be assessed first. So this study was designed to find out the knowledge regarding prevention of cervical cancer by HPV vaccination and its acceptance among women attending OPD of a tertiary hospital.

\section{METHODS AND MATERIALS:}

The present study was conducted among the outdoor patients of Obstetrics \& Gynecology department of Dhaka Medical College Hospital (DMCH), Dhaka from July 2015 to December, 2015. The study period was only 6 months. It was a cross sectional, prospective, observational and single centered study. The aim of the study is to assess the level of awareness among the women attending the OPD of Dhaka Medical College Hospital regarding cervical cancer prevention by vaccination.

The sample was collected from the women attending GOPD of DMCH by random sampling. The sampling was done to select the patient according to the eligibility criteria. Women of reproductive age group who give consent were enrolled in this study. Then the respondents were explained about the study procedure and assurances were given that no benefit or harm would be occurred for being included in this study from their perspective. Sample unit was selected from the study population and data were collected from the selected patient by preformed structured questionnaire, the questionnaire included how HPV could be caught and what it might cause, what they knew about cervical cancer, what they knew about vaccination and acceptance of HPV vaccination. With the demographic details orientation of risk factors, female preponderance cancer, knowledge about cervical carcinoma, vaccination and other prevention procedure as well as source of information's were observed and recorded.

A consent form was prepared. Questionnaire was filled with informed written consent. Expert opinions were taken from specialists of the Department of Gynae \& Obstetrics, pathology, virology department of DMCH, Dhaka. All the data were gathered, accumulated, edited, reduced and decorated. All data were checked and edited after collection. Frequency distribution and normal distribution of all continuous variables were calculated and Chart was prepared by spreadsheet of Windows 7. Data were entered into computer and analyzed with the help of SPSS windows version 17 . 'P' values $<0.05$ was considered as statistically significant. 


\section{RESULT:}

Table- I: Distribution of Patients by clinical characteristics $(\mathrm{n}=229)$

\begin{tabular}{|l|c|c|}
\hline Characteristics & Frequency & Percent \\
\hline Age in years & & 28.4 \\
\hline Below 30 years & 65 & 41.0 \\
\hline $30-39$ & 70 & 30.6 \\
\hline Above 40 years & $34.07 \pm 7.92$ & 10.9 \\
\hline Mean \pm SD & 5 & 54.3 \\
\hline Para & 25 & 19.6 \\
\hline 1 & 9 & 15.2 \\
\hline 2 & 7 & \\
\hline 3 & $2.36 \pm 0.85$ & 28.8 \\
\hline 4 & & 55.9 \\
\hline Mean \pm SD & 65 & 15.3 \\
\hline Age of marriage & 94 & \\
\hline$<13$ years & 70 & 10 \\
\hline $14-18$ years & $16.12 \pm 2.83$ & 51.5 \\
\hline$>18$ years & & 33.2 \\
\hline Mean \pm SD & & 5.2 \\
\hline Education & 23 & 68.12 \\
\hline & 118 & 31.88 \\
\hline Illiterate & 76 & \\
\hline primary & 12 & \\
\hline secondary & & \\
\hline Above secondary & 156 & \\
\hline Monthly income (Taka) & 73 & \\
\hline$<10,000$ & & \\
\hline$>10,000$ & & \\
\hline
\end{tabular}

Figure- 1 shows the psychiatric services provided in the department, $56.32 \%$ were neurological, $33.46 \%$ were musculoskeletal and $7.25 \%$ patients were rheumatologic condition.

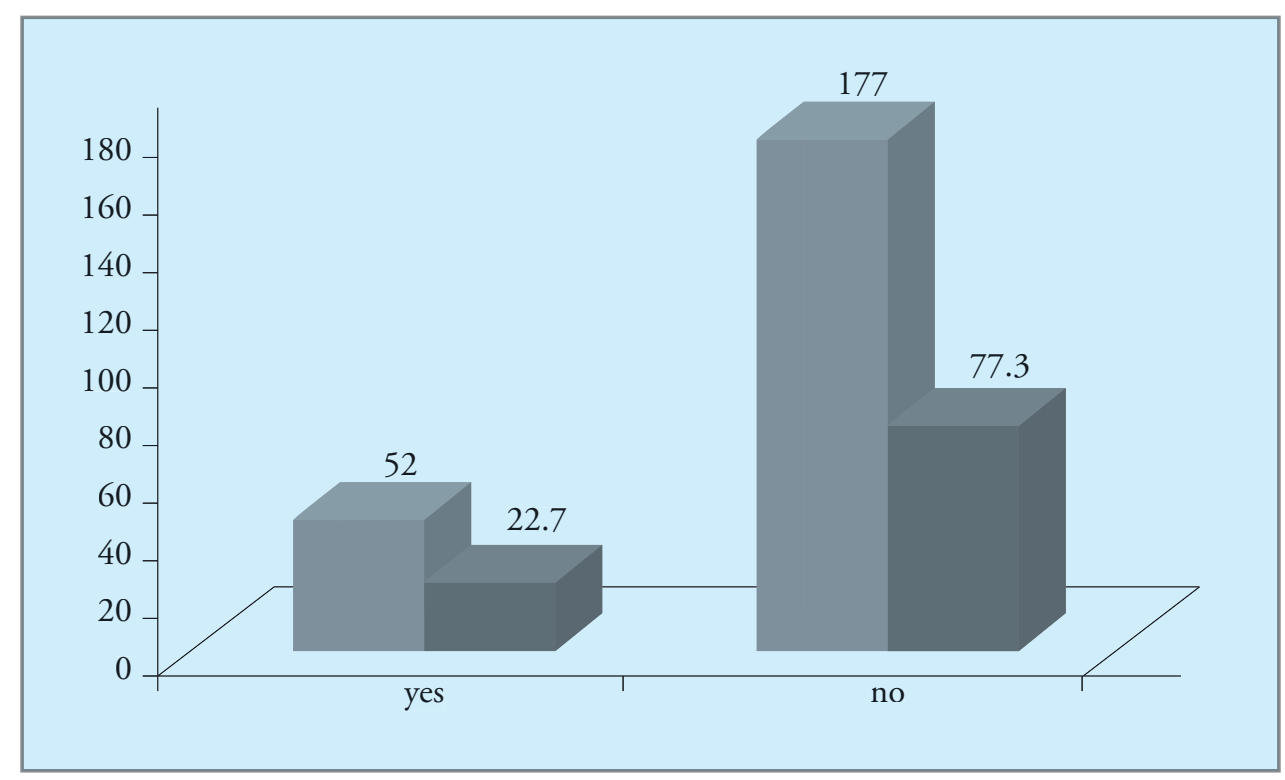

Figure I : knowledge about vaccination $(\mathrm{n}=229)$ 
Table II: Distribution by the knowledge about cervical cancer and vaccination $(\mathrm{n}=229)$

\begin{tabular}{|l|l|l|l|}
\hline Questions & \multicolumn{1}{|c|}{ no } & \% \\
\hline $\begin{array}{l}\text { asked to explain how HPV might be } \\
\text { caught and what it may cause }\end{array}$ & $\begin{array}{l}\text { Kad ever heard about HPV } \\
\text { be caught and what it may cause }\end{array}$ & 42 & 22.7 \\
\hline & $\begin{array}{l}\text { HPV is a sexually transmitted } \\
\text { disease }\end{array}$ & 50 & 21.83 \\
\hline & HPV can cause cervical cancer & 22 & 9.6 \\
\hline & HPV can cause genital warts & 2 & 0.87 \\
\hline & Did not know & 170 & 77.3 \\
\hline & & & \\
\hline & Knowledge about cervical cancer & 58 & 25.3 \\
\hline $\begin{array}{l}\text { asked to explain what they knew } \\
\text { about cervical cancer }\end{array}$ & Did not know & 171 & 74.7 \\
\hline & Knowledge about vaccines & 52 & 22.7 \\
\hline & Did not know & 170 & 77.3 \\
\hline & $\begin{array}{l}\text { Acceptance of vaccination against } \\
\text { HPV }\end{array}$ & 192 & 83.8 \\
\hline
\end{tabular}

Table- II shows distribution by the knowledge about cervical cancer and vaccination where $84 \%$ respondents accepted usefulness of HPV vaccination and wanted to take it.

Table III: Relationship between age of the respondents and knowledge on vaccine $(\mathrm{n}=229)$

\begin{tabular}{|l|l|l|l|l|}
\hline \multirow{2}{*}{ Age } & \multicolumn{2}{|c|}{ Knowledge on vaccine } & \multirow{2}{*}{$X^{2}$} & \\
\cline { 2 - 3 } & Yes & No & \\
\hline Below 30 years & 13 & 52 & & \\
& $20.0 \%$ & $80.0 \%$ & \multirow{3}{*}{3.071} & \multirow{3}{*}{0.215} \\
\hline $30-39$ & 18 & $80.9 \%$ & & \\
\hline Above 40 & $19.1 \%$ & 49 & & \\
& 21 & $70.0 \%$ & & \\
\hline Total & $30.0 \%$ & 177 & & \\
\hline
\end{tabular}

Table III shows women aged more than 40 years have more knowledge which is about $30 \%$.

Table IV: Relationship between education \& income of the respondents with knowledge on vaccine ( $\mathrm{n}=229)$

\begin{tabular}{|c|c|c|c|c|}
\hline & \multicolumn{2}{|c|}{ Knowledge on vaccine } & \multirow{2}{*}{$x^{2}$} & \multirow{2}{*}{$P$} \\
\hline & Yes & No & & \\
\hline \multicolumn{5}{|l|}{ Education } \\
\hline Illiterate & $\begin{array}{l}2 \\
8.7 \%\end{array}$ & $\begin{array}{l}21 \\
91.3 \%\end{array}$ & \multirow{5}{*}{3.071} & \multirow{5}{*}{0.215} \\
\hline Up to primary & $\begin{array}{l}18 \\
15.3 \%\end{array}$ & $\begin{array}{l}100 \\
84.7 \%\end{array}$ & & \\
\hline Above primary & $\begin{array}{l}28 \\
36.8 \%\end{array}$ & $\begin{array}{l}48 \\
63.2 \%\end{array}$ & & \\
\hline Above secondary & $\begin{array}{l}10 \\
83.3 \%\end{array}$ & $\begin{array}{l}2 \\
16.7 \%\end{array}$ & & \\
\hline Total & 58 & 171 & & \\
\hline \multicolumn{5}{|l|}{ Monthly income(Taka) } \\
\hline$<10,000$ & $\begin{array}{l}29 \\
18.6\end{array}$ & $\begin{array}{l}127 \\
81.4\end{array}$ & & \\
\hline$>10,000$ & $\begin{array}{l}23 \\
31.5\end{array}$ & $\begin{array}{l}50 \\
68.5\end{array}$ & & \\
\hline
\end{tabular}

Table IV shows relationship between education \& income of the respondents with knowledge on vaccine, educated respondents who completed above secondary education about $83.3 \%$ had more knowledge about vaccine. 


\section{DISCUSSION:}

Only $25.3 \%$ and $22.7 \%$ of our respondents had some knowledge about cervical cancer and vaccination respectively. Both these figures are very poor. Surveys conducted previously and before the regulatory approval of $\mathrm{HPV}$ vaccines also showed a low level of awareness of HPV (30-40\%)22-25.The results of the present study are in line with other recent studies, carried out after regulatory approval of HPV vaccination, that showed limited levels of awareness of HPV. In the United Kingdom and Italy (where HPV vaccine is free of charge for girls of 12 years of age), only about $24 \%$ and $30 \%$ of respondents, respectively, reported awareness of HPV26,27. We also studied the relationship between HPV awareness and several factors. In this study awareness increased with increase age and education (Table III \& IV). Women from high income group have more knowledge about $31.5 \%$. According to some authors report increasing age (women 14-24 years) and having had a personal, familiar, or friendly history of previous STI or cervical cancer were associated with an increased awareness of HPV and accurate knowledge of the HPV-cervical cancer link24,25,27. In a study only $19 \%$ and $7 \%$ of the participants, respectively, knew that HPV is an STI and that it can cause cervical cancer.28Another study, carried out in north-eastern Brazil, assessing young women (16-23 years) showed similar results to the that study: less than $10 \%$ of participants acknowledged that HPV might lead to cervical cancer; however, a higher proportion of those women (67\%) knew that HPV is sexually transmitted.29This difference might be explained by the fact that these women had higher educational levels than women in that study $(61 \%$ and $50 \%$ respectively had high school education or above).

Regarding acceptability of the vaccine, despite the inadequate knowledge of HPV and cervical cancer, $83.8 \%$ participants reported that they would accept vaccination if the HPV vaccine was available. As other studies have reported, there was a generally favorable attitude toward HPV vaccines; despite the low level of knowledge about the link between HPV and cervical cancer, $91 \%$ and $88 \%$ of women would agree to receive the vaccine in surveys that found that only $15 \% 30$ and $38 \% 31$, respectively, had heard of HPV.

It was in 2006 that HPV vaccines were licensed in the USA for use in females 9 to 26 years of age with the aim of preventing cervical cancer, precancerous lesion and genital warts by HPV $16 \& 18.32$ It was indeed an important milestone. The studies demonstrate $100 \%$ efficacy in the prevention of persistent specific type HPV infections and CIN 2/3, with follow up data available for up to 4 to 5 years among subjects who were strictly adherent to the study protocol. Gardasil also protect against HPV 6, 11, 16 \& 18 related external genital lesion .
Among women aged 15 to 26 years who completed the vaccination regimen, did not violate the protocol and had no virological evidence of infection with respective HPV type at study entry through 1 month after the third dose (vaccine-5301 versus placebo-5258) vaccine efficacy was $100 \%(97.96 \%$ confidence interval[CI], $76 \%$ to100\%) for preventing HPV 16 OR 18 related CIN $2 / 3$ and adenocarcinoma in situ. Fifteen of the placebo cases had CIN 3.33-36

These vaccines only work to prevent HPV infection, not treat the infection that already there.37,38 That is why to be most effective, vaccines should be given before a person exposed to HPV ( through sexual activity).

It is important to realize that no vaccine provides complete protection against all cancer causing types HPV, so routine cervical cancer screening is still necessary. In spite of having preventive measures (screening and vaccination) that can reduce morbidity and mortality from cervical cancer it is difficult to implement, especially in developing countries due to lack of knowledge and partly due to lack of resources. As like success of EPI vaccination program we have to be successful to prevent cervical cancer through HPV vaccination of 9 to 13 aged girls. This study highlights the importance of awareness creation about cervical cancer and its risk factors, screening and importance of vaccination through television, cable line advertisement, poster, billboard and most importantly through health education to prevent cervical cancer.

\section{REFERENCE:}

1. Sultana, R. and Sultana, N. Clinical Profile and Treatment Protocol of Invasive Carcinoma of Cervix. Bangladesh Medical Journal (Khulna),2012; 45, 11-14.

2. WHO/ICO Information Centre on HPV and Cervical Cancer (HPV Information Centre) Human papillomavirus and related diseases report in world. Available athttp://www.hpvcentre.net/statistics/reports/XWX.pdf. Accessed February 24, 2014

3. Ferlay J, Shin HR, Bray F, et al. GLOBOCAN 2008: Cancer incidence and mortality worldwide. IARC Cancer Base. No. 10 Lyon, France: IARC Press; 2010. http://globocan. iarc.fr.

4. Akhter PS, Uddin MM, Sharma SK. Patterns of malignant neoplasm - A three year study, Bangladesh Medical journal 1998;27(20):29-32.

5. levinson, W.Human Papillomavirus. In :revew of medical microbiology and immunology. Levinson, W(eds).10th Ed. The McGraw-Hill Companies,Inc.2008;p:264-5.

6. Winer RL, Hughes JP, Feng Q, et al. Condom use and the risk of genital human papillomavirus infection in young women. New England Journal of Medicine 2006; 
$354(25): 2645-54$.

7. Gnanamony, M.P.A. and Abraham,P. An overview of Human Papillomavirus and current vaccine stratigies. Indian .Journal . Medical. Microbiology. 2007;25(1):10-17.

8. Anorlu ,R.I. Cervical cancer: the Sub-Saharan African perspective. Reported. Health. Matters. 2008;16(32):41-49.

9. Nessa A, Hussain MA, Rahman JN, et al. Screening for cervical neoplasia in Bangladesh using visual inspection with acetic acid. Int J GynaecolObstet, 2010; 111, 115-8.

10. Ashrafun Nessa, KhadizaNurunNahar, Shirin Akhter Begum, ShahinAraAnwary, Fawzia Hossain, KhairunNahar. Comparison between Visual Inspection of Cervix and Cytology Based Screening Procedures in Bangladesh, Asian Pac J Cancer Prev, 2013;14 (12), 7607-11

11. Ahmed T, Ashrafunnessa, Rahman J. Development of a Visual Inspection Programme for Cervical Cancer Prevention in Bangladesh. Elsevier Reproductive Health Matters,2008;16, 78-85

12. Basu P, Nessa A, Majid M et al. Evaluation of the National Cervical Cancer Screening Programme of Bangladesh and the formulation of quality assurance guidelines. J Fam Plann Reprod Hlth Care, 2010; 36, 131-4.

13. Sangwa-Lugoma G, Mahmud S, Nasr SH, et al. Visual inspection as a cervical cancer screening method in a primary health care setting in Africa. Int J Cancer, 119, 2006; 1389-95.

14. World Health Organization. Cervical Cancer Screening in Developing Countries: Report of a WHO consultation. France: WHO Publications, 2002; 1-75.

15. Sankaranarayanan R, Budukh AM, Rajkumar R. Effective screening programmes for cervical cancer in lowand middle-income developing countries. Bull World Health Organ. 2001;79:954-62.

16. WHO/ICO Information Centre on HPV and Cervical Cancer (HPV Information Centre). A Summary report on HPV and Cervical cancer statistics in South Africa.2007. [Accessed 28 August 2015

17. Cervical Cancer Health Guide: Can Cervical Cancer Be Prevented. 2008. http:/www.cancer.org/docroot/content/2_4_2X. Accessed 2009/08/05.

18. Adanu, R.M.K. Cervical Cancer Knowledge and Screening in Accra, Ghana. Journal of Women's Health \& Gender-based Medicine. 2002; 11(6), pp.487-8.

19. Kjaer, S.K. Risk factors for cervical neoplasma in Denmark. APMIS 1998; Suppl. 80.1-41 Abstract.

20. American Cancer Society Guideline for Human Papillomavirus (HPV) Vaccine Use to Prevent Cervical
Cancer and Its PrecursorsCA :Cancer Journal for Clin 2007;57:7-28,

21.Human Papillomavirus (HPV) Vaccines, national cancer center,Morbidity and Mortality Weekly Report 2012; 61(15):258-61.

22.Hanisch R, Gustat J, Hagensee ME, Baena A, Salazar JE, Castro MV, Gaviria AM, Sánchez GI: Knowledge of Pap screening and human papillomavirus among women attending clinics in Medellín, Colombia. Int J Gynecol Cancer. $2008, \quad 18: \quad$ 1020-6. 10.1111/j.1525-1438.2007.01131.x.

23. Waller J, McCaffery K, Forrest S, Szarewski A, Cadman L, Wardle J: Awareness of human papillomavirus among women attending a well woman clinic. Sex Transm Infect. 2003, 79: 320-2. 10.1136/sti.79.4.320.

24. Nøhr B, Munk C, Tryggvadottir L, Sparén P, Tran TN, Nygård M, Skare GB, Dasbach E, Liaw KL, Kjaer SK: Awareness of human papillomavirus in a cohort of nearly 70,000 women from four Nordic countries. ActaObstetGynecol Scand. 2008, 87: 1048-54.

25. Tiro JA, Meissner HI, Kobrin S, Chollette V: What do women in the U.S. know about human papillomavirus and cervical cancer?. Cancer Epidemiol Biomarkers Prev. 2007, 16: 288-94. 10.1158/1055-9965.EPI-06-0756.

26. Marlow LA, Waller J, Wardle J: Public awareness that HPV is a risk factor for cervical cancer. Br J Cancer. 2007, 97: 691-4. 10.1038/sj.bjc.6603927.

27. Di Giuseppe G, Abbate R, Liguori G, Albano L, Angelillo IF: Human papillomavirus and vaccination: knowledge, attitudes, and behavioural intention in adolescents and young women in Italy. Br J Cancer. 2008, 99: 225-9. 10.1038/sj.bjc.6604454.

28. Cristina H Rama, Awareness and knowledge of HPV, cervical cancer, and vaccines in young women after first delivery in São Paulo, Brazil - a cross-sectional study, BMC Women's Health2010; 10.1186/1472-6874-10-35

29. Moreira ED, Oliveira BG, Ferraz FM, Costa S, Costa Filho JO, Karic G: Knowledge and attitudes about human papillomavirus, Pap smears, and cervical cancer among young women in Brazil: implications for health education and prevention. Int J Gynecol Cancer. 2006, 16: 599-603. 10.1111/j.1525-1438.2006.00377.

30. Sauvageau C, Duval B, Gilca V, Lavoie F, Ouakki M: Human papilloma virus vaccine and cervical cancer screening acceptability among adults in Quebec, Canada. BMC Public Health. 2007, 7: 304-10.1186/1471-2458-7-304

31. Kwan TT, Chan KK, Yip AM, Tam KF, Cheung AN, Lo SS, Lee PW, Ngan HY: Acceptability of human 
papillomavirus vaccination among Chinese women: concerns and implications. BJOG. 2009, 116: 501-10. 10.1111/j.1471-0528.2008.01988.

32.Marrazzo JM, Koutsky NB, Kuypers JM, Stine K. Papanicolaou test screening and prevalence of genital human papillomavirus among females who have sex with women. American Journal of Public Health. 2001:91(6):947-52

33. Harper DM, Franco EL, Wheeler CM, et al. Sustained efficacy up to 4.5 years of a bivalent L1 virus-like particle vaccine against human papillomavirus types 16 and 18: follow-up from a randomised control trial. Lancet 2006; 367:1247-1255.

34. Koutsky LA, Ault KA, Wheeler CM, et al. A controlled trial of a human papillomavirus type 16 vaccine. $\mathrm{N}$ Engl J Med 2002; 347:1645-1651.

35. Mao C, Koutsky LA, Ault KA, et al. Efficacy of human papillomavirus-16 vaccine to prevent cervical intraepithelial neoplasia: a randomized controlled trial. ObstetGynecol 2006; 107:18-27.

36. Villa LL, Costa RL, Petta CA, et al. Prophylactic quadrivalent human papillomavirus (types 6, 11, 16, and 18) L1 virus-like particle vaccine in young women: a randomised double-blind placebo-controlled multicentre phase II efficacy trial. Lancet Oncol 2005; 6:271-278.

37. Hildesheim A, Herrero R, Wacholder S, et al. Effect of human papillomavirus 16/18 L1 viruslike particle vaccine among young women with preexisting infection: A randomized trial. JAMA 2007; 298(7):743-753.

38. Schiller JT, Castellsague X, Garland SM. A review of clinical trials of human papillomavirus prophylactic vaccines. Vaccine 2012; 30 Suppl 5:F123-138. 